\title{
Effectiveness and acceptance of commercially available protein-rich meals and dairy products in increasing protein intake of community-dwelling older adults
}

\author{
Joost O. Linschooten ${ }^{1}$, Janne Beelen ${ }^{2}$, Jos Borkent ${ }^{2}$, Marian A. E. de van der Schueren ${ }^{2}$ and \\ Annet J. C. Roodenburg ${ }^{1}$ \\ ${ }^{1}$ HAS University of Applied Sciences, Den Bosch, Netherlands and \\ ${ }^{2}$ HAN University of Applied Sciences, Nijmegen, Netherlands
}

\section{Abstract}

Introduction: Home-delivered hot meals and dairy could possibly prevent community-dwelling (CD) older adults from becoming malnourished when they are no longer able to cook themselves. Ideally, these products contribute to an intake of 1.2 grams of protein per $\mathrm{kg}$ bodyweight per day (g/kg BW/d) and $\geq 25$ grams of protein per main meal. This study evaluated the effectiveness of these products on protein intake and explored the acceptance of these products.

Methods: The study was a single-blind RCT with CD older adults switching from self-prepared to commercially-available homedelivered hot meals and dairy products during 28 days. The intervention group (I) received meals and dairy products high in ( $\geq$ $20 \mathrm{EN} \%$ ) protein; the control group (C) received standard meals and dairy products low(er) in protein. Dietary intake was measured at baseline, two weeks (T1) and four weeks (T2) by a three-day food diary. After study completion, 25 participants (aged $>80 \mathrm{y}, 16$ female/9 male) participated in focus groups discussing information on healthy eating, attitude towards high protein products, product acceptance.

Results: Ninety-eight CD older adults (mean age: 80.4 years \pm 6.8 ). Baseline protein intake was 1.09 (SE 0.05) (I) and 0.99 (SE 0.05) (C) $\mathrm{g} / \mathrm{kg} \mathrm{BW} / \mathrm{d}$. During the trial, protein intake of I remained stable at $1.12 \mathrm{~g} / \mathrm{kg} \mathrm{BW} / \mathrm{d}$ (SE 0.05$)$ while intake decreased in $\mathrm{C}$ to 0.87 (SE 0.03). More I participants reached the threshold of $\geq 25$ grams protein at dinner compared to $C$ but not at breakfast and lunch. In the focus groups, participants indicated to be aware of the importance of healthy eating (less salt and less fat). However, knowledge on high-protein products was low and participants did not know why intake of protein should be increased. Less social interaction was indicated as one of the main causes of deterioration of eating behaviour. Further, participants indicated that they primarily would like to enjoy eating instead of focusing on functionality. The ready-made meals were generally considered to be too large and low in vegetables.

Conclusions: Switching from self-prepared meals to ready-made meals carries the risk of a decreasing protein intake in CD older adults. To stimulate a healthy dietary pattern, focus should be on behavioural change and knowledge improvement. Besides awareness for healthy eating, food enjoyment is essential. Finally, meal composition could be improved to enhance acceptance.

\section{Conflict of Interest}

Products are provided by Frieslandcampina \& Sligro Food Group 